\title{
Agile Product Development Governance - On Governing the Emerging Scrum/Stage-Gate Hybrids
}

\author{
Anita Friis Sommer ${ }^{1}$, Iskra Dukovska-Popovska ${ }^{2}$, and Kenn Steger-Jensen ${ }^{2}$ \\ ${ }^{1}$ Engineering Design Centre, Department of Engineering, University of Cambridge, UK \\ afs35@cam.ac.uk \\ ${ }^{2}$ Center for Logistics, Department of Mechanical and Manufacturing, Aalborg University, DK \\ \{Iskra, Kenn\}@celog.dk
}

\begin{abstract}
Product Development (PD) management is changing through the emergence and implementation of agile principles into existing PD frameworks. This process changes PD governance assets, even though this aspect is not yet described in existing literature. Thus, this paper introduces PD governance of agile/stage-gate hybrid solutions through a comparative study including five case companies supported by a review of existing literature. The results include an overview of applied governance assets including which are supportive for PD management. The study indicates that only assets not part of corporate governance are affected by the introduction of agile, and that unaltered corporate assets affect PD performance of the hybrid solutions negatively.
\end{abstract}

Keywords: Product development governance, agile product development, scrum, stage-gate models, case study.

\section{Introduction}

Globalization is believed to be a major driver of increasing competition, generating higher customer expectations and thus shorter product life cycles [1]. In this globalized world, the competitive industrial company is the one that succeeds in being open and flexible to any customer demand, while still developing and producing highquality products at low cost [2][3]. From a systems perspective we can see PD processes evolving from fitting the description of a closed deterministic system to approaching more the definitions of an open system. Indeed, complex PD processes are more accurately described through open-system models, including a number of un-determined influential external factors.

To support the PD management process the majority of large industrial companies have generic process models or process standards [4]. The generic process model includes a visual representation of the series of main activities in the PD process often sorted in a series of stages and gates [5]. The process model is accompanied by corresponding PD methods describing how to use the model during the PD process. Furthermore, PD is enabled by PD process governance, which entails the supporting management processes and supporting mechanisms of the organization. While much research has been concerned with PD process improvement and PD management methods, only few articles focus on PD governance. 
PD governance has emerged from project governance, among others, where a major and recent trend is concerned with governance from an institutional perspective [6]. In 2007 Patel [7] even used the phrase 'governance movement'. The aim of PD governance is to support the PD process in achieving long-term value [8]. Hence, PD governance is of major importance for PD performance, yet little research is concerned with governance of complex PD processes [9], which includes the open system PD processes of interest in this paper. One of the latest branches of research on PD management is agile PD, which has recently emerged (in the early 10's) on managing the increasing complexity of the PD process using agile methods. The agile methods originate from the software development industry and are now increasingly being adapted by, among others, research and development in industrial companies. Recent academic findings include Cooper [10], who shows that agile methods are applied within the context of existing stage-gate PD models, and Ovesen [11], who in 2012 conducted a multiple case study of industrial manufacturers implementing Scrum. Scrum is one of the dominant agile PD frameworks, including agile process model, methods and PD governance. The findings indicate that companies significantly improve PD performance after implementation, but that the agile framework is merged into the existing PD standards rather than replacing them.

This paper is concerned with exploring PD governance of the agile/stage-gate hybrid solutions, which are currently emerging in industry for the purpose of developing theoretical proposals for further research on PD governance. The paper includes a theoretical background of PD governance, agile PD with focus on Scrum, and an introduction to Scrum governance. Afterwards, is a presentation of a multiple case study method and the involved case companies, followed by an overview of the case study findings, discussion of the results, and finally proposals for further research.

\section{Theoretical Background}

Governance is an emerging aspect of PD management and an area of increasing attention [12-14]. Governance is a set of management systems, rules, protocols, relationships, and structures that provides the framework within which decisions are made to achieve the intended business or strategic motivation [15]. A PD governance system includes an overall governance structure with supporting governance assets (adapted from Weill and Ross [16]), which is illustrated in Figure 1.

Agile PD is one of the latest branches of research that recently emerged (in the early 10's) within industrial PD management. Agile methods are specialized in managing highly complex PD including active customer involvement. The agile methods originate from the software development industry and have now been adapted to new PD research in the context of the manufacturing industry. Recent academic findings include Cooper [10], who shows that agile methods are applied within the context of existing stage-gate models, and Ovesen [11], who in 2012 conducted a multiple case study of seven Danish manufacturers implementing the agile PD method called 'Scrum', which included an agile process model and governance of PD projects into 


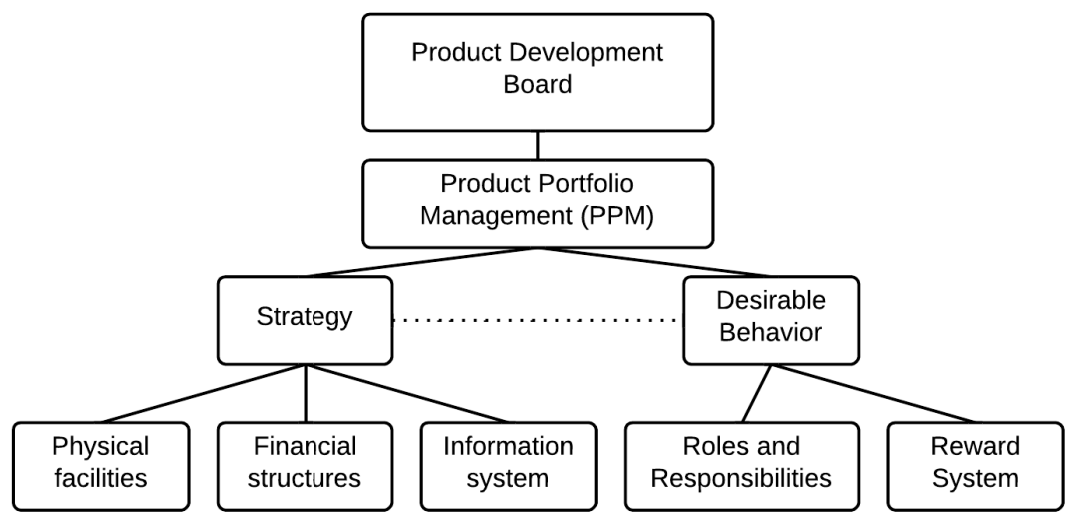

Fig. 1. Supporting governance assets Weill and Ross [16]

the existing traditional PD solution. The findings indicated that companies significantly improved PD performance after implementation. These findings are supported by Sandmeier, Morrison and Gassmann [17] reporting of increased PD performance and improved customer integration after implementation of the agile PD method 'Extreme Programming' at three large German manufacturers. Hence, empirical studies show that mass-producers can benefit significantly from implementation of agile/stage-gate hybrid PD methods. Furthermore, the agile methods support the trend of increased active customer involvement in especially the early phases of the PD process [18]. The trend encourages companies to engage in collaborative PD since the agile methods enable a flexible PD method supporting active involvement. Thus, the agile/stage-gate hybrid methods seem to fit managing PD as an open system (including the considerations for ongoing change and thus high uncertainty) and active customer collaboration. However, there are no prior case studies on the corresponding PD governance assets supporting these hybrid PD solutions.

\subsection{Scrum Governance}

Scrum was originally exclusively a software development framework or, rather, a generic PD standard. Scrum has recently gained interest in agile PD in industrial companies due to the positive impact on PD performance [11, 19]. The Scrum Guide, which is the official Scrum guidebook, includes a toolbox of interconnected project management methods and a process model. The process model is the visualization of the Scrum activity-flow which works as a visual coupling of the Scrum methods [20].

The governance assets within Scrum governance differ significantly from traditional PD governance. Generally, physical facilities are not well defined for traditional PD. However, Scrum includes a set of distinct required physical facilities. Each active scrum team must have a dedicated project room, where they are physically located throughout the development process. Furthermore, the project rooms are equipped with at least one large white board (called the scrum board), used for visually displaying the sprint process, burn-down chart, and product backlog. On the other 
hand financial structures are as little described in Scrum as is the case for traditional PD. Hence, it is relevant to notice that the goal for PD management frameworks is to improve PD performance including financial performance, and at the same time the determining financial structures are undefined. The same situation occurs for both information systems and reward systems for PD management, which generally remain undescribed in both Scrum and traditional PD frameworks. However, roles and responsibilities are well described in existing frameworks with distinct variations. The Scrum roles are the product owner, scrum master, and scrum team, which have a set of distinct responsibilities as described in Table 1.

Table 1. Scrum roles and responsibilities

\begin{tabular}{ll}
\hline Scrum Roles & \multicolumn{1}{c}{ Responsibilities } \\
\hline \multirow{3}{*}{ Product Owner } & - Clearly express product backlog items \\
& - Order product backlog items to best achieve goals and missions \\
& - Ensure the value of the work the development team performs \\
& - Ensure the development team understands items in the product backlog \\
\hline & - Clearly communicate vision, goals, and product backlog items \\
& - Teach participants to create clear and concise product backlog items \\
& - Facilitate Scrum events as requested or needed \\
Scrum Master & - Coach in self-organization and cross-functionality \\
& - Remove impediments to the Development Team's progress \\
& - Plan Scrum implementations within the organization; \\
& - Help employees and stakeholders understand and enact Scrum \\
\cline { 2 - 3 } Team & - Self-organize - turning product backlog into product increments \\
& - Cross-functional collaboration \\
& - Share accountability in the Development Team as a whole \\
& - Avoid sub-teams dedicated to particular domains \\
\hline
\end{tabular}

In contrast, traditional PD frameworks generally operate with a steering committee, a project manager, an a project team. The steering committee is responsible for strategic decisions, whereas the project manager is responsible for all tactical and operational decisions including both project and process management. The project team does not have management responsibilities and are only responsible for finalizing assigned tasks.

Hence, there are significant differences between traditional PD governance and Scrum governance, but some governance assets still remain undefined within both. Since companies increasingly implement Scrum in combination with traditional PD methods, it is relevant to explore how governance systems are correspondingly affected by the emerging hybrid solutions. Therefore, we ask the research question: "What are the applied governance assets in practice, in cases of scrum/stage-gate hybrid methods for product development management?" 


\section{$3 \quad$ Method}

In order to answer the research question, an explorative comparative case study has been conducted including five large companies with different product types in different industries. The companies were selected based on their maturity in hybrid/stagegate solutions to include companies with experience in using them, and thus the chosen companies had implemented their solutions between 2-5 years prior to the study. An overview of the companies is presented in Table 2.

Table 2. Case studies on agile PD governance

\begin{tabular}{lllll}
\hline Company & Product types & $\begin{array}{l}\text { Number of } \\
\text { employees }\end{array}$ & Company type & Data \\
\hline D & Pharmaceuticals & 37,000 & Industrial mass-producer & $\begin{array}{l}\text { 3SI, 1 GI, 1 OS, } \\
\text { PM, ID. }\end{array}$ \\
E & Plastic Toys & 10,000 & Industrial mass-producer & 2 SI, PM, ID \\
F & Electronics & 170 & Industrial mass-producer & 2 SI, PM, ID \\
G & Windows & 10,000 & Industrial mass-producer & 16 GI, PM, ID \\
H & $\begin{array}{l}\text { Cross-country } \\
\text { power lines }\end{array}$ & 700 & Energy Construction and & 24 SI, 6 GI, 1 \\
& service provider & WS, PM, ID. \\
\hline
\end{tabular}

$\mathrm{SI}=$ single interviews, GI= Group Interviews, OS=Observations studies, WS=Workshops, $\mathrm{PM}=$ Project Management standards, ID=Internal Documents.

A multiple case study approach was chosen to enhance the possibility of attaining rich data hence allowing greater depth and clarity [21]. Furthermore, a multiple case study creates the opportunity to compare results across the case contexts and develop a broader and more generalizable understanding of the phenomenon. The data was analysed through open coding and sampling according to governance assets into a conceptually ordered display. The interview study findings were strengthened through triangulation to company internal documents and company project management standards for PD.

\section{$4 \quad$ Results}

The results have been structures according to the five governance assets, and overview of applied assets in the case companies is presented in table 3 .

Physical facilities include project rooms with scrum boards in four out of the five companies, which were implemented together with Scrum. These facilities enabled and enhanced process visibility and knowledge sharing both within the team and towards PD stakeholders. The company without dedicated facilities was in a process 
Table 3. Case studies on agile PD governance

\begin{tabular}{llllll}
\hline & \multicolumn{5}{c}{ Governance assets in case companies } \\
\cline { 2 - 6 } Cases & Physical facilities & $\begin{array}{l}\text { Financial } \\
\text { Structures }\end{array}$ & $\begin{array}{l}\text { Information } \\
\text { System }\end{array}$ & $\begin{array}{l}\text { Reward } \\
\text { System }\end{array}$ & $\begin{array}{l}\text { Roles and } \\
\text { responsibilities }\end{array}$ \\
\hline D & $\begin{array}{l}\text { Portfolio board, PR } \\
\text { and SB }\end{array}$ & $\begin{array}{l}\text { No Ac- } \\
\text { count }\end{array}$ & None & KPI & Hybrid \\
E & PR and SB & Dedicated & Rally & KPI & Hybrid \\
F & PR and SB & Dedicated & None & KPI & Hybrid \\
G & PR and SB & Dedicated & None & KPI & Hybrid \\
H & No dedicated facili- & Dedicated & None & KPI & Hybrid \\
\hline
\end{tabular}

$\mathrm{PR}=$ Project Room, $\mathrm{SB}=$ Scrum Board, Dedicated $=$ Dedicated project account

No Account $=$ No dedicated account within projects, owned and managed financially by R\&D department. Hybrid = Scrum team with project manager as project owner and liaison to a steering committee.

of implementing these due to recognition of the possible benefits. Company D furthermore had a portfolio board displaying the PD projects publically within the company enhancing visibility across PD projects. Based on the cases, project rooms with scrum boards are regarded an essential part of PD governance of agile/stage-gate hybrids. Four of five cases have dedicated account to PD projects as part of the financial structure. The dedicated accounts allow for PD managers to purchase resources from the surrounding organization and make the project independent from other activities. Company D had no dedicated accounts, and based on this experienced difficulties in finalizing PD projects towards internal customers, and challenges in 'borrowing' specialized resources especially from manufacturing. Thus, dedicated accounts are considered to be the preferred financial solution for PD governance. Regarding the information system, only company E had implemented an information system to support the agile PD process, however the effects were still too immature to materialize. Hence, for information system asset it is deduced that this governance asset is not yet part of hybrid PD governance practice. The reward systems were not affected through implementation of scrum, and the Key Performance Indicators (KPI) system was applied in all five cases. Even so, this entailed challenges due to a mismatch between the rigidity of the system and the level of change in PD projects. Hence, even though the KPI system is present in all cases, it is not the ideal solution, and practitioners call for more flexible adaptable reward solutions. Finally, the Roles and Responsibilities included a hybrid between traditional PD and agile PD. For all companies, the Scrum terminology has been adapted including product owners, Scrum masters, and a self-organizing development team. However, all cases also had steering committees consisting of line managers and management stakeholders. Through the implementation process, the former project managers had become product owners, whereas selected team members had been trained scrum masters. 


\section{Discussion and Conclusions for Further Research}

In a majority of the cases PD governance assets include; dedicated project rooms, Scrum boards, dedicated project accounts, and hybrid project roles as supporting governance mechanisms. Hence, these governance assets are relevant for further studies on advantages of hybrid PD including explanatory research developing theories to explain why these solutions work in practice. Furthermore, the cases suggest that there is potential for improving PD performance in further improvement of agile/stage-gate governance, and thus we call for further research on agile PD governance effects on PD performance.

However, some assets were not affected by the introduction of agile, which were the information system and a KPI reward system. These two assets are generally part of corporate governance, since they expand to the entire company. Based on this finding, we suggest that implementation of agile/stage-gate hybrids affect the PD governance system towards more agile governance assets, however only for assets not influencing corporate governance. Thus further research is recommended on the affect of corporate governance on PD performance especially in cases with agile/stage gate hybrids.

A final conclusion on the study is related to the generalizability of the emerging hybrid governance assets. The assets were identified across five companies in different markets, and based on this study we suggest that it is possible to develop a prescriptive generic model for hybrid PD governance, which is applicable across industries, and thus we also call for further applied research on this subject.

\section{References}

1. Jou, Y.T., Chen, C.H., Hwang, C.H., Lin, W.T., Huang, S.J.: A study on the improvements of new product development procedure performance-an application of design for Six Sigma in a semi-conductor equipment manufacturer. International Journal of Production Research 48, 5573-5591 (2010)

2. Soosay, C.A., Hyland, P.W., Ferrer, M.: Supply chain collaboration: capabilities for continuous innovation, Supply Chain Management. An International Journal 13, 160-169 (2008)

3. Hilletofth, P., Eriksson, M.D.: Coordinating new product development with supply chain management. Industrial Management \& Data Systems 111, 6-6 (2011)

4. Haque, B.: Problems in concurrent new product development: an in-depth comparative study of three companies. Integrated Manufacturing Systems 14, 191-207 (2003)

5. Cooper, R.G.: Overhauling the New Product Process. Industrial Marketing Management 25, 465-482 (1996)

6. Clegg, S.R., Pitsis, T.S., Rura-Polley, T., Marosszeky, M.: Governmentality matters: designing an alliance culture of inter-organizational collaboration for managing projects. Organization Studies 23, 317-337 (2002)

7. Patel, D.: Why executives should care about project governance; What your peers are doing about it. PM World Today 9, 165-187 (2007) 
8. Klakegg, O.J., Williams, T., Magnussen, O.M., Glasspool, H.: Governance frameworks for public project development and estimation. Project Management Journal 39, S27-S42 (2008)

9. Klakegg, O.J.: Challenging the Interface between governance and management in construction projects. In: 5th Nordic Conference on Construction Economics and Organisation (2009)

10. Cooper, R.G.: What's Next? After Stage-Gate. Research Technology Management 57, 20-31 (2014)

11. Ovesen, N.: The Challenges of Becoming Agile: Implementing and Conducting Scrum in Integrated Product Development. In: Department of Architecture \& Design, Aalborg University, Aalborg (2012)

12. Sanderson, J.: Risk, uncertainty and governance in megaprojects: A critical discussion of alternative explanations. International Journal of Project Management 30, 432-443 (2011)

13. Baker, M., Bourne, M.: A Governance Framework for the Idea-to-Launch Process: Development and Application of a Governance Framework for New Product Development. Research-Technology Management 57, 42-49 (2014)

14. Sommer, A.F., Dukovska-Popovska, I., Steger-Jensen, K.: Barriers towards Integrated Product Development:-a holistic project management perspective. International Journal of Project Management (2013)

15. Bekker, M.C., Steyn, H.: Project governance for global projects. In: Technology Management for the Global Future, PICMET 2006, pp. 2195-2202. IEEE (2006)

16. Weill, P., Ross, J.W.: IT governance on one page. CISR WP 349 (2004)

17. Sandmeier, P., Morrison, P.D., Gassmann, O.: Integrating Customers in Product Innovation: Lessons from Industrial Development Contractors and In House Contractors in Rapidly Changing Customer Markets. Creativity and Innovation Management 19, 89-106 (2010)

18. Franke, N., Schreier, M.: Why Customers Value Self-Designed Products: The Importance of Process Effort and Enjoyment. Journal of Product Innovation Management 27, 1020$1031(2010)$

19. Schwaber, K.: Agile project management with Scrum. Microsoft Press, Redmond (2009)

20. Boehm, B., Turner, R.: Management challenges to implementing agile processes in traditional development organizations. IEEE Software 22, 30-39 (2005)

21. Yin, R.: Case Study Research: Design and Methods. Sage, CA (1994) 